\title{
IRAWAN SEBAGAI KORBAN MEDAN PERANG \\ DALAM PERISTIWA KEMATIAN IRAWAN \\ MENURUT SASTRA LAKON TRADISI PEDALANGAN YOGYAKARTA
}

\author{
Bambang Sulanjari \\ Universitas PGRI Semarang \\ bbgsljir@gmail.com
}

\begin{abstract}
Abstrak
Naratif Kematian Irawan menurut tradisi pedalangan Yogyakarta telah mengalami "pergeseran" dari induknya: Mahabharata Sansekerta. Menurut tradisi pedalangan Yogyakarta Irawan mati sebelum perang baratayuda dimulai. Naratif kematian Irawan seperti itu, tidak dijumpai dalam Mahabharata Sansekerta maupun kitab-kitab Jawa Kuna.

Pergeseran letak naratif kematian Irawan dalam tradisi pedalangan Yogyakarta tersebut, tampaknya bukan hal yang tanpa alasan, karena lakon yang memuat naratif tersebut termasuk Lakon Baratayuda, yaitu lakon yang dikeramatkan dan sangat ketat diwariskan. Untuk memahami kasus ini dilakukan pengkajian tokoh seperti yang pernah dilakukan oleh Alf Hiltebeitel yang berhasil menembus makna Mahabharata melalui pendekatan epik, mite, dan ritual.

Peristiwa kematian Irawan dalam tradisi pedalangan Yogyakarta erat kaitannnya dengan Baratayuda. Terbunuhnya Irawan rupanya menyarankan ke arah upacara korban pada tataran ritual. Naratif kematian Irawan tersebut rupanya mengacu pada pemujaan kepada Durga pembunuh Mahisasura. Dengan terlaksananya korban Irawan, maka Pandawa pun memperoleh jaminan kemenangan dalam Baratayuda.
\end{abstract}

Kata kunci: kematian Irawan; tradisi pedalangan Yogyakarta; pendekatan epik, mite dan ritual

\section{Abstract}

The death of Irawan narrative in the tradition of Yogyakarta puppetry has undergone a "shift" of the origin text: Sanskrit Mahabharata. According to the tradition of Yogyakarta puppetry Irawan die before the Baratayuda war began. Irawan death narrative as such, is not found in the Sanskrit Mahabharata and the books of the Old Javanese.

Shifting the narrative the death of Irawan in Yogyakarta puppetry tradition, it seems is not without reason, because the lakon that contains the narrative included Baratayuda lakon, that lakon is sacred and very tight inherited. To understand this case do figures study such ever undertaken by Alf Hiltebeitel who was penetrates the meaning of the Mahabharata through epic, myth, and ritual approach. 
Irawan death scene in the traditions of Yogyakarta puppetry connected closely with Baratayuda. The kill of Irawan apparently suggested direction sacrifice at the level of ritual approach. The death of Irawan narrative was apparently referring to the cult of Durga Mahisasura killer. With the implementation of Irawan victim, the Pandavas victory was assured in Baratayuda.

Key words: the death of Irawan; the tradition of Yogyakarta puppetry; epic, myth, and ritual approach

\section{PENDAHULUAN}

Seperti halnya kitab suci Hindu yang lain, misalnya kitab-kitab Veda, Mahabharata juga mengalami penyebaran ke berbagai bagian dunia yang menjadi wilayah penyebaran Hindu, termasuk beberapa daerah di Indonesia. Berdasarkan sumber tertulis, Mahabharata mulai dikenal di Jawa pada masa pemerintahan $S r i$ Maharaja Sri Dharmawangsa Teguh Anantawikramottunggadewa, dengan adanya "penjawaan" kitab-kitab yang merupakan bagian dari epik Mahabharata, ke dalam Bahasa Jawa Kuna (Zoetmulder, 1985: 109-113). Dalam rentang perjalanan dari negeri asal ke wilayah penyebarannya, Mahabharata mengalami proses yang disebut transformasi. Dalam rangka transformasi tersebut ruang dan waktu memegang peran yang sangat penting (Manu, 1993/1994: 4 dst.). Proses transformasi mengakibatkan adanya berbagai bentuk baru Mahabharata, menurut tanggapan akar budaya pada ruang dan waktu yang disinggahinya. Di Jawa pada era sastra Jawa Kuna misalnya, Mahabharata ditransformasikan dalam kitab-kitab parwa dan kakawin. Pada era yang lain, Mahabharata ditransformasikan dalam lakon-lakon wayang (Manu, 1993/1994: 8). Dengan demikian dapat dikatakan bahwa lakon-lakon wayang, dalam hal ini adalah wayang kulit purwa, sebenarnya merupakan satu rangkaian yang berkesinambungan yang bersumber pada Mahabharata (dan Ramayana), meskipun belum dapat dipastikan tradisi yang mana yang menjadi sumber transformasi tersebut (Manu, 1993/1994: i).

Bentuk-bentuk baru Mahabharata hasil penyesuaian terhadap ruang dan waktu seperti tersebut di atas, tentunya mengalami berbagai pergeseran jika dibandingkan dengan karya aslinya. Akibatnya baik naratif, tokoh dan keberadaannya, makna maupun fungsinya, mempunyai warna yang baru pula (Manu, 1993: 4). Dalam tradisi pedalangan, orang sering memandang pergeseran tersebut sebagai penyimpangan yang harus diluruskan, dan sering dikatakan bahwa tradisi ini tidak masuk akal, tradisi itu tidak masuk akal dan sebagainya. Lebih jauh lagi gejala yang tampak pada tradisi pedalangan di Jawa saat ini adalah adanya usaha yang dilakukan oleh sebagian pendukung suatu tradisi untuk mencampur-adukkan berbagai tradisi. Fakta lain yang juga terlihat adalah usaha "pengembalian" lakon-lakon wayang - yang dianggap menyimpang - ke tradisi yang dianggap lebih benar, entah itu Mahabharata tradisi Jawa Kuna atau tradisi Sansekerta. Jika tindakan semacam ini berlarut-larut, maka tidak mustahil dugaan Wiryamartana tentang kemungkinan hilangnya tradisi lokal yang kaya dengan seluk-beluk dan rinciannya yang khas (Wiryamartana, 1988: 10-11), akan segera 
terjadi. Akibatnya, tradisi lokal tersebut sulit dilacak keberadaannya, terlebih bagi para peneliti yang akan mendalami seluk-beluk tradisi dan transformasi.

Tindakan-tindakan seperti tersebut diatas - meskipun bukan golongan tindakan yang melanggar hukum - sebenarnya tidak perlu terjadi, jika para pendukung tradisi pedalangan mengetahui lakon-lakon wayang menurut tradisi atau bahkan versi yang digelutinya. Apalagi jika mengetahui latar belakang mitis dan ritual terjadinya lakon-lakon wayang, mengingat Mahabharata di dunia pewayangan mengalami transformasi berkat pertumbuhan lakon-lakon yang mempunyai latar belakang mitos dan legenda tersendiri (Wiryamartana, 1988: 10), sehingga setiap tradisi mempunyai cara tersendiri pula untuk mengungkapkannya.

Di lingkungan tradisi pedalangan Yogyakarta, Mahabharata ditranformasi dalam bentuk lakon-lakon wayang yang sebagian besar khasanah cerita dan rinciannya yang khas masih beredar dan diwariskan secara lisan (Wiryamartana, 1988: 11). Keadaan semacam ini memungkinkan adanya pergeseran dan perbedaan. Perbedaan-perbedaan semacam ini hendaknya tidak disikapi sebagai penyimpangan, tetapi disadari sebagai cabang tradisi yang merupakan kekayaan yang tak ternilai harganya.

\section{Metode Penelitian}

Pendekatan Mahabharata melalui keberadaan tokoh-tokohnya bukanlah sesuatu yang baru. Beberapa peneliti seperti Alf Hiltebeitel, Medelaine Biardeau, dan Ruth Cecily Katz sudah melakukannya. Alf Hiltebeitel berhasil menembus makna Mahabharata melalui pendekatan epik, mite, dan ritual. Oleh Sang Kavi Mahabharata, ketiga hal itu berhasil dilihat sebagai hal yang saling berhubungan dan saling melengkapi (Hiltebeitel, 1990: 359-360). Jika Mahabharata hanya dipandang sebagai epik, akan terlihat di dalamnya banyak keganjilan, dan keganjilan-keganjilan dalam epik tersebut sering menyebabkan kebuntuan. Untuk mengatasi hal tersebut, dengan diilhami para peneliti sebelumnya, seperti Stig Wikander dan Domezil, Hiltebeitel menyarankan studi ke arah hubungan antara epik dan mite. Yang dimaksud mite di sini adalah cerita dalam bentangan ruang dan waktu, yang berhubungan dengan masalah kosmologi dengan pelaku utama para dewa (Hiltebeitel, 1990: 29-32). Dikatakan juga oleh Hiltebeitel bahwa dalam Mahabharata, epik merupakan bagian integral dari mite, atau dengan kata lain epik dan mite saling berintegrasi (Hiltebeitel, 1990: 15).

Pendekatan dari segi epik dan mite saja dipandang belum cukup oleh Hiltebeitel. Pendekatan mitis harus dilanjutkan dengan pendekatan ritual. Pendekatan ini didasari oleh keberadaan Sang Kavi Mahabharata: Vyasa, dalam kapasitasnya sebagai seorang rsi. Kemampuan melihat yang dimiliki oleh seorang $r s i$, memungkinkan ia melihat bukan saja hubungan epik dan mite, tetapi juga hubungan epik dan ritual (Hiltebeitel, 1990: 359-360), sehingga tidak mustahil jika Mahabharata mengisahkan bahwa seorang pahlawan pada tataran epik dapat diidentifikasikan sebagai sarana ritual - seperti pasubandha - pada tataran ritual (Manu, 1993/1994: 27).

Pendekatan terhadap peristiwa kematian Irawan ini akan mengikuti jalan pemikiran Hiltebeitel di atas. Campur tangan mite dalam epik pada dunia 
pewayangan tampak jelas dengan hadirnya para dewa yang berdampingan dengan tokoh-tokoh pada tataran epik. Selain ciri tersebut, hubungan epik dan mite dalam dunia pewayangan dapat juga dimengerti antara lain melalui konsep avatara, 'titisan'. Tokoh Kresna, raja Dwarawati, dikenal dengan baik sebagai titisan Visnu, sehingga kemampuan-kemampuan yang dimilikinya sebagai tokoh epik, sering dihubungkan dengan keberadaannya sebagai titisan Visnu. Dari kenyataan itu terlihat kemanunggalan antara Visnu sebagai tokoh mitis dan Kresna sebagai tokoh epik. Dengan demikian Kresna adalah Visnu yang hadir pada tataran epik. Tentu saja masih diperlukan pengkajian lebih lanjut terhadap kedua tokoh itu untuk mengetahui hubungan antara keduanya.

\section{HASIL DAN PEMBAHASAN}

\section{a. Naratif Kematian Irawan}

Kematian Irawan menurut tradisi pedalangan Yogyakarta juga mengalami "pergeseran" dari induknya: Mahabharata Sansekerta. Menurut tradisi pedalangan Yogyakarta Irawan mati sebelum perang baratayuda dimulai. Naratif kematian Irawan dalam tradisi pedalangan di Yogyakarta, terdapat dalam Lakon Seta Gugur. Lakon ini merupakan Lakon Baratayuda yang kedua (Radyomardowo, 1978: 5). Meskipun lakon ini disebut Lakon Baratayuda yang kedua, tetapi perang Baratayuda yang sesungguhnya baru terjadi pada pertengahan menjelang akhir lakon tersebut, setelah Irawan menemui ajalnya. Pada bagian awal lakon itu baru diceritakan persiapan terakhir menjelang perang Baratayuda. Untuk mendapatkan sedikit gambaran tentang Lakon Seta Gugur tersebut, berikut ini disajikan ringkasan ceritanya :

Duryudana merasa sedih atas kematian ayahnya: Dhastharatha, dan ibunya: Gendari atas ulah Kresna. Durna berpendapat, berhubung sudah membawa korban Dhastharatha dan Gendari, lebih baik Baratayuda segera dimulai. Setelah semua setuju, Duryudana segera menunjuk Salya sebagai senapati dan Durna sebagai senapati pengamping. Kemudian diadakan pembagian pakuwon, 'kubu': Duryudana berkubu di Bulu Pitu, Karna di Setra Gilang dan Bogadenta di Sela Gajah. Patih Sengkuni memerintahkan agar pasukan Ngastina segera menduduki medan Kurusetra dan membunyikan isyarat perang, serta mendahului menggempur pasukan Pandawa. Dewi Srikandhi bersama dengan Setiyaki dan Udawa yang berada di Pakuwon Glagah Tinunu dikejutkan oleh kedatangan pasukan Ngastina. Mereka bertiga segera bersiaga, maka terjadilah pertempuran hebat. Srikandhi, Setiyaki dan Udawa akhirnya menarik diri dari arena pertempuran karena mereka belum mendapat perintah dari atasan untuk memulai perang Baratayuda. Sementara itu Irawan yang sedang dalam perjalanan menuju Wiratha dibunuh oleh Kala Srenggi yang bermaksud menuntut balas pada Arjuna atas peristiwa yang menimpa orang tuanya di masa yang lalu. Srikandhi menemui Irawan sudah tidak bernyawa. Kala Srenggi segera dicari dan akhirnya dapat dibunuh. Srikandhi segera melanjutkan perjalanannya ke Wiratha. Di Wiratha, Prabu Maswapati dan para Pandawa sedang mendengarkan keterangan dari Kresna tentang hasil lawatannya ke Ngastina sebagai duta terakhir Pandawa untuk 
mengambil haknya: negara Ngastina. Pembicaraan itu terpotong oleh kedatangan Srikandhi yang mengabarkan kematian Irawan dan kedatangan pasukan Ngastina. Kresna segera mencanangkan dimulainya Baratayuda dengan menunjuk Utara dan Wiratsangka sebagai senapati pihak Pandawa. Pertempuran dahsyat segera terjadi. Setelah berhasil membuat kocar-kacir pasukan Ngastina, Utara dan Wiratsangka tewas ditangan Salya dan Durna. Seta yang tengah bertapa di Gunung Suhini, dipanggil untuk menggantikan kedudukan Utara dan Wiratsangka. Berkat kesaktiannya, Seta berhasil memukul mundur pasukan Ngastina, bahkan putra Salya yang bernama Rukmarata tewas olehnya. Melihat kenyataan itu, Duryudana mengambil langkah untuk menghadapi Seta dengan mengangkat Bisma sebagai senapati. Berkat panah Cucuking Dhandhang pemberian ibunya: Dewi Gangga, Bisma berhasil membunuh Seta. Setelah Seta gugur Srikandhi duduk sebagai senapati Pandawa. Akhirnya Bisma terbunuh oleh Srikandhi dengan panah Bramastra. Mendengar Bisma terbunuh, Bogadenta mengamuk, tetapi dihentikan oleh Sengkuni, karena sebelum kematiannya, Bisma berpesan: barang siapa memulai membuat masalah akan mengalami kekalahan dalam Baratayuda. Lagipula Bogadenta belum mendapat perintah dari Duryudana dan para tetua Ngastina.

Ringkasan cerita di atas diambil dari Kaset Wayang Kulit Lakon Seta Gugur (selanjutnya disingkat KWKLSG), produksi Kusuma Recording, kode produksi: KWK 067 dengan Dhalang Ki Hadisugito, dari Toyan, Wates, Kulonprogo, Yogyakarta.

Naratif kematian Irawan seperti tersebut di atas, tidak dijumpai dalam Mahabharata Sansekerta maupun kitab-kitab Jawa Kuna. Mahabharata Sansekerta menyebutkan Irawan (Aravan), terbunuh di medan pertempuran pada hari kedelapan (Hiltebeitel, 1988: 317). Bhismaparwa Jawa Kuna menceritakan Irawan (Irawan) terbunuh dalam pertempurannya melawan Raksasaryasrnggi, pada hari kedelapan perang Kuruksetra (Gonda, 1936). Dua kitab kakawin yang memuat naratif kematian Irawan menyatakan hal yang sama, Irawan terbunuh dalam perang Bharatayuddha. Kakawin Irawantaka menceritakan, ketika melihat Arjuna terdesak, Irawan datang membantu sampai akhirnya ia sendiri terbunuh (Saktimulya, 1987: 31-33), sementara dalam kakawin Bharatayuddha hanya disebutkan Irawan mati oleh Srnggi di medan pertempuran, tanpa disertai dengan uraian tentang peristiwa kematiannya (Gunning, 1903: XII. 17).

Pergeseran letak naratif kematian Irawan dalam tradisi pedalangan Yogyakarta tersebut, tampaknya bukan hal yang tanpa alasan, karena lakon yang memuat naratif tersebut termasuk Lakon Baratayuda, yaitu lakon yang dikeramatkan dan sangat ketat diwariskan (Wiryamartana, 1985: 15). Baratayuda menurut Wiryamartana adalah ketentuan sang nasib. Nasib para wirawan dalam perang tersebut berkaitan erat dengan asal-usul kelahirannya, sumpah yang pernah diucapkan, kutuk yang pernah diterima, perbuatan masa lalu yang harus mendapat balasan dan seterusnya (Wiryamartana, 1985: 21). Demikian pula nasib Irawan ini, sangat ditentukan oleh masa lalunya. 
Peristiwa kelahiran Irawan diwarnai oleh maya. Mulai dari Siva (Bathara Guru) yang menerapkan maya-nya dengan mengubah dirinya menjadi seorang raja bernama Dewa Kumala, sampai dengan tempat di mana Irawan dilahirkan yang juga disamarkan oleh Siva. Irawan sendiri mulai saat kelahirannya berada dalam naungan Siva yang sedang menerapkan maya-nya hingga Siva mengakhiri maya-nya (Sulanjari, 1998: 37-64). Maya yang meliputi Irawan pada peristiwa kelahirannya itu akan membawa dampak tersendiri pada sepak terjang Irawan di masa-masa kemudian. Sebagai contoh, keberhasilan Irawan dalam merebut tahta Ngastina dalam Lakon Antasena Ngraman dan Lakon Wahyu Widayat adalah keberhasilan semu: maya. Keberhasilan Irawan itu tidak disertai kemampuannya menduduki singgasana (dhampar) Ngastina, bahkan tahta yang sudah direbutnya harus dikembalikan lagi kepada Duryudana, karena menurut Kresna belum saatnya tahta Ngatina diambil alih keluarga Pandawa (Sulanjari, 1998: 85-87).

Kematian Irawan juga diwarnai maya. Irawan mati dalam baratayuda yang maya, artinya bukan baratayuda yang sesungguhnya. Hal ini dapat dilihat dari lakon yang memuat peristiwa kematian Irawan, yang disebut sebagai Lakon Baratayuda yang kedua. Meskipun disebut Lakon Baratayuda kedua, tetapi Baratayuda yang sesungguhnya baru terjadi pada bagian pertengahan menjelang akhir dari lakon ini. Di samping itu, meskipun peristiwa kematian Irawan terjadi sebelum Baratayuda dimulai, tetapi kematian Irawan terjadi pada saat ia bermaksud begabung dengan pasukan Pandawa untuk menjalani perang Baratayuda yang sesungguhnya (Sulanjari, 1998: 87).

\section{b. Penyebab Kematian Irawan}

Lakon Seta Gugur mengisahkan, pada waktu Irawan bermaksud pergi ke Wiratha untuk bergabung dengan pasukan Pandawa, ibunya: Wanohara mencegahnya. Tetapi Irawan sebagai anak muda keturunan Pandawa, merasa menjadi tulang punggung keluarga Pandawa, oleh karena itu ia merasa wajib ikut berperang demi negara. Akhirnya Irawan memaksakan kehendaknya pergi ke Wiratha. Keberangkatan Irawan tersebut ternyata berakibat fatal, Irawan justru menemui ajalnya sebelum sampai di Wiratha (KWKLSG: IVA). Dari bentangan Lakon Seta Gugur diketahui ada dua penyebab kematian Irawan. Penyebab pertama dikatakan oleh Kresna dalam percakapan di kerajaan Wiratha:

Maswapati: "Putu prabu."

Kresna: "Wonten paring pangandika eyang."

Maswapati: "Adhimu srikandhi kang ngaturake sirnane putuku irawan."

Kresna: "Inggih mekaten menika mboten perlu dipun-getuni, awit menika terang yen ta yoga kula irawan mbladhak milang sipat mirang kampuh jingga, nerak paugeran, mboten mituhu dhumateng pengendikanipun kadang kula yayi Wanohara. Janaka ya ora kena nyucuh garwamu."

Janaka: “Inggih." (KWKLSG. VI)

Pada percakapan di atas dikatakan oleh Kresna bahwa Irawan mati karena melanggar paugeran. Jika ditarik kebagian depan lakon tersebut akan terlihat yang 
dimaksud dengan paugeran oleh Kresna itu, yaitu apa yang telah dikatakan oleh Wanohara kepada Irawan ketika mendengar akan segera terjadi perang Baratayuda:

Irawan: "Yen mekaten boten wonten awonipun ingkeng putra kedah sowan dhateng negari Wiratha nyuwun supados dipundados-aken senapati.

Wanohara: "Aja ya ngger aja, awit dhawuhe wong atuwamu ora ngemungake Irawan kabeh para putra-putra pancen ora kena lunga, awit wong tuwa kang bkal jumangkah pribadi wong tuwa kang bakal angentasi gawe murih bisa ngrebut kamukten Ngestina, besok satemah kamukten iku bakal kagem para putra-putra."

Irawan: "Menika naminipun, tiyang enem ingkeng kagengen kamukten, boten saged ndherek menggalihaken kawontenan negari Ngamarta tuwin negari Wiratha, mangka cara ingkeng putra, ingkang limrah menika kedah ingkeng enem ingkeng tumandang rumiyin, tiyang asepuh menika sekeca lenggah kanthi ambotohi kewala sampun cekap, dados wonten menapa-menapa cekap para putra-putra mboten kok malah sing enem disingkirake sing tuwa malah padha temandang."

Wanohara: "Kaya mengkono kuwi dhawuhe para pinisepuh awit wong enom kang supaya disingkirake mbesuk akir tembe bakal bisa nyambung sejarah." (KWKLSG. IV A)

Dari transkip teks di atas diketahui bahwa yang dimaksud paugeran adalah larangan bagi para putra Pandawa untuk ikut terjun dalam kancah perang Baratayuda. Larangan ini dikelurkan oleh Pandawa dengan tujuan agar kelak ada penerus keturunan (nyambung sejarah) keluarga Pandawa.

Keberanian Irawan melanggar larangan orang tuanya didasari oleh dharma, sebagaimana diketahui bahwa dharma seorang ksatriya adalah berperang. Dharma itu mutlak dilaksanakan, karena seorang ksatriya yang tidak mau menjalankan dharma-nya, yaitu berperang, akan kehilangan kehormatannya (Pendit, 1989: 42). Bharatayuda bagi para ksatriya adalah ajang untuk menunaikan dharma-nya, itulah sebabnya ketika Wanohara menahan kepergian Irawan, Irawan tetap pada pendiriannya untuk ikut serta dalam pertempuran mengambil kembali milik Pandawa: Negara Ngastina. Kesetiaan Irawan pada dharma telah menyebabkan kematiannya. Dengan demikian, meskipun Irawan belum sampai di medan pertempuran yang sesungguhnya, tetapi kematiannya adalah demi dharma.

Penyebab yang kedua adalah kekeliruan Kala Srenggi. Penyebab kedua ini didasari oleh satu peristiwa yang menyebabkan kelahiran Kala Srenggi. Peristiwa tersebut terjadi dalam Lakon Kuntulwilanten atau disebut juga Lakon Bimakurda Gugur. Adapun ringkasan ceritanya pernah ditulis oleh A. Nugroho, sebagai berikut:

"Prabu Jathagimbal jatuh cinta kepada Dewi Kuntulwilanten, untuk itu ia minta bantuan kepada Arjuna agar terlaksana keinginannya bertemu Kuntulwilanten. Arjuna memenuhi permintaan itu dengan cara mendandani 
Jathagimbal hingga mirip dengan Arjuna. Dalam wujud sebagai Arjuna itulah Jathagimbal mendekati Kuntulwilanten. Dalam pada itu, Dewi Jathagini juga sedang dilanda asmara kepada Arjuna. Jathagini datang menemui Kuntulwilanten, minta bantuan agar dapat dipertemukan dengan Arjuna. Kuntulwilanten mendandani Jathagini hingga persis dengannya agar Arjuna mau menerima. Dari siasat dan tipuan itulah justru bertemu Arjuna palsu dan Kuntulwilanten palsu yang tidak lain adalah kakak beradik Jathagimbal dan Jathagini. Mereka berkasihmesra tanpa menyadari siapa sebenarnya dirinya. Dari hubungan tersebut kelak lahirlah Kala Srenggi (Nugroho, 1986: 39)

Peristiwa di atas juga diulas oleh Ki Hadisugito dalam Lakon Seta Gugur melalui percakapan antara Kala Srenggi dan ibunya: Jathagini, di Gua Siwamangleng, ketika Kala Srenggi menanyakan siapa ayahnya, tetapi Ki Hadisugito menyebut ayah Kala Srenggi dengan nama Jathayaksa, raja Giri Kadhasar. Jathayaksa sendiri akhirnya mati di tangan Arjuna dalam usahanya menuntut balas atas perlakuan Arjuna terhadapnya yang dianggap sebagai penyebab peristiwa yang menimpanya bersama Jathagini, adik kandungnya sendiri (KWKLSG: III B-IV A).

Tindakan Arjuna yang telah membikin malu orang tuanya, bahkan telah membunuh orang tuanya tersebut yang menyebabkan Kala Srenggi bermaksud menuntut balas kepada Arjuna.

Kala Srenggi: "Weh ladala, yen ngaten wajibipun kula males wirang utawi males pejah kaliyan Janaka." (KWKLSG: IV A)

Males wirang dan males pejah itulah yang menjadi tujuan Kala Srenggi. Dengan bekal sedikit pengetahuan tentang ciri-ciri Arjuna yang didapat dari ibunya ia berangkat mencari Arjuna. Ketika bertemu Irawan, ia menyangka bahwa Irawan itulah Arjuna, karena Irawan memiliki ciri-ciri fisik seperti yang disebutkan oleh ibunya. Tanpa berpikir panjang dibunuhlah Irawan:

. . kocapa Raden Kala Srenggi, ingkang wonten ing jumantara, priksa kumelaping ageman kang sarwa seta gya tumiyup mulat marang pasuryanira Raden Irawan kang bagus warnane, kagungan panyakrabawa yen ta iki Raden Janaka. Sigra tumiyup saking jumantara, Raden Irawan kasaut jangganira, kabakem tugel thel. Wus noyah-nayuh baskara titi mangsa ambruking kunarp . . kunarpa bareng kulawan pesating yitma, Raden Irawan sirna merga layu ( KWKLSG : IV A).

Dari kutipan di atas terlihat bahwa sebenarnya yang diinginkan Kala Srenggi adalah Janaka (Arjuna), oleh karena itu lunaslah sudah hutang wirang: 'malu' dan pejah: 'kematian' Arjuna.

Perbuatan Kala Srenggi tersebut berkaitan dengan karma yang harus diterima Arjuna karena perbuatan Arjuna di masa lampau. Meskipun akhirnya yang terbunuh Irawan, tetapi Arjuna sebagai orang tua Irawan tetap juga menanggung akibatnya, yaitu kehilangan putranya.

Agaknya kaitan antara dharma, karma dan Bharatayuda sudah dimulai di sini. Seperti diketahui bahwa Baratayuda bukan sekedar pertempuran antara baik 
dan buruk atau benar dan salah, tetapi lebih berkaitan dengan dharma dan karma. Mahabharata Sansekerta sendiri mengungkapkan bahwa kemenangan tertinggi adalah dharma; serbuan secara nyata tidak diterima di medan perang; yang harus dimenangkan adalah yuddha, 'perang' yang bekecamuk dalam diri manusia dalam kesadaranya yang paling bawah (Manu, 1996: 567). Menurut Wiryamartana perang Baratayuda lebih bersifat sebagai ketentuan sang nasib. Nasib para wirawan dalam perang tersebut berkaitan erat dengan peristiwa atau perbuatan pada masa lalu (Wiryamartana, 1985: 85). Meskipun saat kematian Irawan, Baratayuda yang sesungguhnya belum dimulai, tetapi kematian-kematian sudah merupakan takdir. Hal ini terbukti dengan telah diambilnya kembali pusaka Kresna Sekar Wijayakusuma milik Kresna - yang mempunyai kemampuan menghidupkan orang mati yang belum saatnya - oleh para dewa sebagai pengganti Pakeming Baratayuda, 'pedoman perang Baratayuda', yang disebut Jitapsara yang diminta oleh Kresna (Radyomardowo: 17-25). Di samping itu Lakon Seta Gugur yang memuat naratif kematian Irawan sudah termasuk dalam rangkaian Lakon-Lakon Baratayuda, tepatnya Lakon Baratayuda yang kedua, oleh karena itu tidak mustahil jika dharma dan karma sudah mewarnai berbagai peristiwa dalam lakon ini. Dari uraian di atas terlihat bahwa dharma dan karma sangat berperan dalam rangka kematian Irawan.

\section{c. Parinaya-Yuddha-Rajya}

Misteri kematian Irawan tersebut tampaknya secara tidak langsung berkaitan dengan penelitian Manu yang berjudul "Parinaya di Kurusetra: Arjuna sebagai Durgabhakta dalam Lakon Seta Ngraman Tradisi Pedalangan Ngayogyakarta" (Manu, 1995). Sebagaimana di India, di Jawa pun Arjuna mendapat tempat yang istimewa. Dalam dunia pewayangan Arjuna dikenal memiliki status lelananging jagat lancuring bawana. Keberadaan Arjuna semacam itu diwujudkan dengan diperistrinya beberapa putri, seperti: Sembadra, Srikandhi, Larasati, Sumarsih, Wanohara dan lain-lain, bahkan juga para bidadari dari kayangan (Manu, 1995: 38).

Dengan acuan tulisan Harman, Manu mengatakan bahwa parinaya-parinaya (pernikahan) yang dijalani oleh Arjuna adalah sacred marriage, yang berhubungan dengan kebaktian personal pada dewa, bukan sekedar metafora pertanian (Manu, 1995: 14-16). Disebutkan juga bahwa ada tiga hal pokok yang melekat dan saling berkaitan secara serasi pada diri Arjuna, yaitu: yuddha (perang); parinaya (pernikahan); dan rajya (kerajawian). Yuddha yang dijalaninya demi dharma-nya sebagai ksatriya selalu mendatangkan anugerah: artha, baik berupa parinaya maupun rajya. Demikian pula parinaya yang dijalaninya, selalu berhubungan dengan yuddha dan rajya (Manu, 1995: 11-20). Parinaya Arjuna dengan para putri baik dari bumi maupun dari kayangan akan selalu membawa dampak positif bagi kelangsungan keberadaan Arjuna beserta saudara-saudaranya (Manu, 1995: 20 ).

Berpijak pada uraian di atas, dapat diduga bahwa parinaya Arjuna dengan Wanohara akan membawa dampak positif bagi Arjuna atau Pandawa. Parinaya Arjuna dengan Wanohara membuahkan seorang anak, yaitu Irawan yang 
kematiannya telah menyelamatkan Arjuna. Seperti telah dibahas di atas bahwa yang dimaksud oleh Kala Srenggi ketika membunuh Irawan adalah Arjuna. Setelah membunuh Irawan, Kala Srenggi lalu mati di tangan Srikandhi. Dengan demikian Arjuna bebas dari ancaman Kala Srenggi, sehingga dapat menunaikan dharma-nya dalam perang Baratayuddha. Dengan kemenangan Arjuna dan saudara-saudaranya, berarti negeri Ngastina dapat diperoleh kembali. Irawan dalam hal ini menjadi jembatan terhubungnya yuddha, parinaya dan rajya.

\section{d. Irawan sebagai Korban Medan Perang}

Alf Hiltebeitel pada tahun 1988 membukukan penelitiannya tentang Mahabharata versi Tamil. Dalam penelitiannya tersebut Hiltebeitel menjumpai kisah Irawan (Aravan) yang tidak terdapat dalam Mahabharata Sansekerta: ketika tiba waktunya untuk menyelenggarakan korban medan perang (kalappali), Pandava mengalami kesulitan dalam menentukan siapa yang akan dijadikan korban. Sementara itu Krsna mengatakan hanya ada empat orang yang pantas dijadikan korban, yaitu: Salya, yang berdiri di pihak Duryodhana: Arjuna, yang mana Pandava tidak bisa kehilangan dia; Krsna, yang mana Pandava juga tidak bisa kehilangan dia, bahkan Dharma (Yudhisthira) mengatakan lebih baik ia kembali ke hutan jika tanpa Krsna; Aravan, yang telah berjanji akan berkorban untuk Duryodhana. Bagi Aravan berkorban untuk Duryodhana sama dengan berkorban untuk orang tuanya sendiri, karena Duryodhana adalah saudara sepupu ayahnya: Arjuna. Akhirnya Krsna dengan siasatnya berhasil mengambil alih Aravan, sehingga Aravan dapat berkorban untuk Pandava tanpa mengingkari janjinya pada Duryodhana. Upacara korban medan perang (Kalappali) ini ditujukan kepada Viramankali untuk memperoleh jaminan kemenangan dalam perang besar di Kuruksetra (Hiltebitel, 1988: 320-332).

Letak naratif kematian Irawan dalam tradisi pedalangan Yogyakarta mempunyai kemiripan dengan peristiwa korban Aravan di Tamil. Jika korban Aravan di Tamil dipersembahkan untuk kepentingan Bharatayuddha, maka peristiwa kematian Irawan pun pasti erat kaitannnya dengan Baratayuda, mengingat tetap dipertahankannya adegan kematian Irawan - yang sepintas lalu tidak ada kaitannya dengan Lakon Seta Gugur - sebelum Baratayuda dalam Lakon Seta Gugur.

Kematian Irawan dalam tradisi pedalangan Yogyakarta rupanya juga menyarankan ke arah upacara korban pada tataran ritual. Tokoh Irawan memenuhi kriteria sebagai korban. Menurut Hiltebeitel, nama Irawan (Tamil: Aravan), yang dalam tradisi Sanskerta adalah Iravan, diderivasi dari kata ida-vant yang berarti: "he who possessed the ida". Sedangkan ida menurut Biardeau: "is the part of the oblatory substance'consumed in common by the participants', from which comes all the fecundity of the sacrifice" (Hiltebitel, 1988: 320). Lebih jauh lagi dalam kalappali diperlukan seorang korban yang "should be handsome, truthful, observant of customs,... ”(Hiltebitel, 1988: 321).

Korban Aravan pada awal Mahabharatayuddha versi Tamil menurut Hiltebeitel diilhami oleh pemujaan pada Durgamahisasuramardini, 'Durga pembunuh kerbau (Mahisasura)' (Hiltebitel, 1988: 318-320). Kematian Irawan 
dalam tradisi pedalangan Yogyakarta pun rupanya mengacu pada pemujaan pada Durga pembunuh Mahisasura. Hal ini dapat dilihat pada peristiwa yang mengikuti terbunuhnya Irawan, yaitu pembunuhan Kala Srenggi oleh Srikandhi, yang agaknya juga mengacu pada mitologi Durga pembunuh Mahissura. Tentang identifikasi Srikandhi sebagai Durga dan Kala Srenggi sebagai Mahisasura ini masih memerlukan penelitian yang lebih mendalam. Sekedar dugaan awal bahwa Srikandhi ini adalah titisan seorang Dewa yang bernama Sang Hyang Gloganetri atau Sang Hyang Durganetri, yang dapat diartikan 'mata Durga'. Dalam Lakon Gerbong Bale Lumur atau disebut juga Lakon Srikandhi Jemparingan, Srikandhi adalah tokoh yang menerima anugerah dewa yang berupa Gerbong Bale Lumur yang sebenarnya adalah penjelmaan dari bungkus bayi Bathari Durga. Sementara itu ke-Mahisasura-an Kala Srenggi dapat dilihat dari namanya. Asura ditunjukkan dengan Kala yang dalam tradisi pewayangan merujuk pada raksasa (asura), sedangkan Mahisa ditunjukkan dengan Srenggi. Menurut Zoedmulder kata srnggi - dalam Bahasa Sansekerta srnggin - berarti 'horned', "(ia yang) bertanduk" (Zoedmulder, 1982: 1817).

\section{SIMPULAN}

Dengan terlaksananya korban Irawan, maka Pandawa pun memperoleh jaminan kemenangan dalam Baratayuda. Dalam Lakon Seta Gugur, Srikandhi berhasil mengakhiri sepak terjang Bisma dengan pusakanya "Kyahi Bramastra", pusaka yang sebelumnya dipergunakan untuk membunuh Kala Srenggi. Keberhasilan Srikandhi ini menunjukkan adanya keterkaitan antara peristiwa pembunuhan Irawan - yang seakan-akan hanya peristiwa yang tidak ada hubungannya dengan keseluruhan lakon - dengan Lakon Seta Gugur. Dengan terkuaknya misteri kematian Irawan ini, maka dapat dimengerti mengapa peristiwa kematian Irawan yang "menyimpang dari sumbernya" itu tetap dipertahankan keberadaannya dalam Lakon Seta Gugur.

Tulisan ringkas ini baru merupakan hasil penelitian awal terhadap peristiwa kematian Irawan menurut tradisi pedalangan Yogyakarta. Hiltebeitel ketika meneliti pemujaan Draupadi di Tamil, pernah mengatakan bahwa dalam rangka studi transformasi, Mahabharata Sansekerta tetap memegang peran yang sangat penting untuk memahami hasil-hasil transformasinya. Demikian pula sebaliknya, bentuk-bentuk transformasi akan sangat membantu untuk memahami Mahabharata. Dalam penelitian ini penulis belum mengaitkan data penelitian ini dengan Mahabharata Sansekerta, sehingga belum memberikan hasil yang cukup memuaskan.

\section{DAFTAR PUSTAKA}

Gonda, J. 1936. Het Oudjavaansche Bhismaparwa, Bibliothecha Javanica 7. Bandung: A. C. Nix \& Co.

Hadisugito, Ki. Seta Gugur. Kaset Wayang Kulit Produksi Kusuma Recording no KWK 067. 
Hiltebeitel, Alf. 1988. The Cult of Drupadi, Mythologies: From Gingee to Kuruksetra I. Chicago dan London: The University of Chicago.

. 1990. The Ritual of Battle, Krishna in The Mahabharata. Albany: State University of New York Press.

Manu. 1993. "Pasubandha di Kuruksetra: Durgapuja menurut Lakon Baratayuda Tradisi Pedalangan Ngayogyakarta”. Laporan Penelitian Fakultas Sastra Universitas Gadjah Mada.

. 1993/1994. "Sapa dan Satya di Kuruksetra: Durna Gugur Dalam Lakon Rubuhan Dalam Tradisi Pedalangan Ngayogyakarta". Laporan Penelitian Fakultas Sastra Universitas Gadjah Mada.

. 1995. "Parinaya di Kuruksetra: Arjuna Sebagai Durgabhakta dalam Lakon Seta Ngraman Tradisi Pedhalangan Ngayogyakarta”. Makalah Temu Ilmiah IX Badan Kerjasama Pengelola Studi Bahasa - Sastra - Budaya Daerah Nusantara Antar Perguruan Tinggi Nasional.

Nugroho, Akhmad. 1986. "Lakon Carangan dalam Pewayangan: Kreativitas atau Pengrusakan ?" dalam Soedarsono, dkk., ed. Lakon carangan dan Citra Pahlawan dalam Pewayangan dan Sastra Jawa. Yogyakarta: Dep. P dan K dirjen Kebudayaan Proyek Penelitian dan Pengkajian Kebudayaan Nasional/Javanologi.

Pendit, Nyoman S. 1989. Bhagavadgita. Jakarta: Yayasan Dharma Sarathi.

Radyomardowo, R. L. dkk. 1978. Serat Baratayuda, cet. V. Yogyakarta: N.V.B.P. Kedaulatan Rakyat.

Saktimulya, Sri Ratna. 1987. "Kakawin Irawantaka, Tinjauan Panciptaan dan Fungsinya”. Skripsi Sarjana Fakultas Sastra Universitas Gadjah Mada.

"Serat Pedhalangan Ringgit Purwa Ngayogyakarta Lampahan Gerbong Bale Lumur Inggih Sinebat Lampahan Srikandhi Jemparingan”. 1966. Naskah koleksi Manu.

Sulanjari, Bambang. 1998. "Peristiwa Kelahiran Irawan Menurut Tradisi Pedhalangan Ngayogyakarta". Skripsi Sarjana Fakultas Sastra Universitas Gadjah Mada.

Wiyamartana, I. Kuntara. 1985. "Transformasi Wiracarita Mahabharata dalam Pewayangan Jawa: Tinjauan Khusus Baratayuda Tradisi Yogyakarta", dalam Soedarsono, dkk., ed. Citra Pahlawan dalam Kebudayaan Jawa. Yogyakarta: Proyek Penelitian dan Pengkajian Kebudayaan Nusantara/ Javanologi Dirjen Kebudayaan dep. P dan K.

. 1988. "Transformasi Wiracarita Mahabharata dalam Pewayangan II", dalam Citra Yogya. No. 003/th. 1.

Zoetmulder, P. J. 1982. Old Javanese-English Dictionary. Netherlands: 'SGravenhage - Martinus Nijhoff. 
. Kalangwan: Sastra Jawa Kuno Selayang Pandang. Cet II, terj. Dick Hartoko.

Jakarta:

Djambatan.

1985. 